\title{
PENGEMBANGAN MEDIA PEMBELAJARAN IPS SEJARAH MELALUI APLIKASI SWAY BERKONTEN INDIS DI SMP NEGERI 8 MADIUN
}

\author{
Khoirul Huda \\ Program Studi Pendidikan Sejarah, FKIP Universitas PGRI Madiun \\ khoirulhuda@unipma.ac.id
}

\begin{abstract}
Abstrak
Pendidikan di Indonesiadilihat dari sudut padang kekinianbanyak mengalami berbagai problema yang multikompleks. Peran pendidik dalam mendayagunakan kondisi pembelajaran melalui komposisi perangkat mengajar belum terberdaya. Minimnya dalam merancang model, strategi atau media yang kurang memadai. Kondisi ini sering terlihat di SMP Negeri 8 Madiun. Berdasarkan pengamatan menyebutkan Pertama, model pengajaran IPS Sejarah masih konvensional dengan metode ceramah. Pendidik belum memanfaatkan variasi media menarik dan interaktif sehingga menimbulkan kejenuhan. Kedua, keterbatasan pemanfaatan sumber ajar. Padahal sumber belajar lingkungan sekitar dapat digunakan untuk pembelajaran IPS Sejarah seperti bangunan Indis (Perumahan Karyawan KA, Gedung sekolah SMPN 1 Madiun, Balai Kota, PLTA Giringan, pabrik gula pagotan dan kawedanan Uteran atau kebun Kopi kandangan). Tujuan penelitian ini adalah mengembangkan media Office Sway berkonten Indis sampai terbentuk draft prototype yang telah diuji. Jenis penelitian adalah Research and Development. Hasil penelitian adalah padauji terbatas di SMP Negeri 10 Madiun diperoleh skor rerata 4,23 menghasilkan skor sangat baik $(X=>4,21)$ sehingga media dianggap layak. Uji skala diperluas di SMP Negeri 8 Madiun menunjukkan rerata 60,35 (pre-test) dan 94,46 (post-test), dan dilakukan uji statistik Paired Samples $T$ Test. Hasil nilai signifikansi adalah 0.00 , sehingga hasil hitung menunjukkan lebih kecil dari 0,05 dan artinya $H_{0}$ ditolak sehingga telah terjadi peningkatan yang signifikan.
\end{abstract}

Kata Kunci: pengembangan, Sway, kebudayaan Indis

\begin{abstract}
Education in Indonesia is seen from the perspective of the present field experiencing many multicomplex problems. The role of educators in utilizing learning conditions through the composition of teaching tools has not been powerless. Minimnya in designing models, strategies or media that are not adequate. This condition is often seen in SMP Negeri 8 Madiun. Based on the observations mention First, the teaching model of IPS History is still conventional with the lecture method. Educators have not taken advantage of interesting and interactive media variations leading to saturation. Second, the limitations of resource utilization. Whereas the surrounding environment learning source can be used for learning IPS History such as Indis building (Housing Employee KA, SMPN 1 Madiun School Building, City Hall, Giringan PLTA, pagotan sugar factory and kawedanan Uteran or Kandangan coffee garden). The purpose of this research is to develop the media office Sway berkonten Indis to form a draft prototype that has been tested. Research type is Research and Development. The result of this research is limited test at SMP Negeri 10 Madiun got average score 4.23produce very good score ( $X$ $=>4.21)$ so media is considered feasible. The expanded scale test at SMP Negeri 8 Madiun shows the average of 60.35 (pre-test) and 94.46 (post-test), and statistic test of Paired Samples $T$ Test. The result of significance value is 0.00 , so the result shows less than 0.05 and $H_{0}$ means rejected so that there has been a significant increase.
\end{abstract}

Keywords: development, Sway, Indie culture

\section{PENDAHULUAN}

Pendidikan di Indonesiadilihat

dari sudut padang kekinianbanyak

mengalami berbagai problema yang

multikompleks, terutama sinerginitas komponen pengajaran. Hal ini karena, peran pendidik dalam mendayagunakan kondisi pembelajaran melalui komposisi perangkat mengajar belum terberdaya. Minimnya pendidik dalam merancang 
model, strategi atau media yang kurang memadai. Pendidik sering terjebak terhadap pusaran konvensionalisme denganstrategi belajar yang berorientasi pada model ceramah variatifyang hanya dipadukan dengan buku teks. Relasi yang dilakukan masih satu arah yaitu teacher centered, terutama pembelajaran IPS Sejarah. Paradigmatersebut kadang membuat bosan, tidak menarik dan membuat sasaranmateri pelajaran kurang nampak. Integrasi dalam memberdayagunakan komponen belajar dengansistem teknologi juga mendukung untuk menghasilkan konsep mengajar yang baik. Berbagai terapan aplikasi dapat dimanfaatkan untuk merancang pembelajaran yang menarik. Keberadaannya memberi peluang pendidik untuk merancang pembaharuan pengajaran yang bermakna. Masalah pengajaran IPS Sejarah adalah minimnyamemahami materi yang berhubungan dengan wawasan kebangsaan. Wawasan kebangsaan yang dipunyai oleh generasi sekarang menunjukkan grafik menurun. Kehidupan pluralisme sebagai kekhasan bangsa tidak dapat maknai secara prospektif.

Pada sisi lain, proses
pembelajaran yang efektif perlu
didorong ke desainyang konstruktif.
Pendidik membangun penyadaran
identitas melalui kekhasan hasil
kebudayaan
masa
laludalam
pembelajaran
IPS
Sejarah.

Pengembangan mediadan kombinasinya dirasa berpeluang untuk mengembangkan pengajaran yang modern. Di era globalisasi dibutuhkan pula skema mengajar yang tidak hanya mementingkan hasildimensi kognitif saja, melainkan diperlukan suatu formulasi pengajaran guna mencapaiketerbangunan identitas kebangsaan (Novi Triana Habsari dan Khoirul Huda, 2015: 361). Untuk itu, diperlukanredesain media pembelajaranyang membantu menciptakanmeaningful learningdan salah satunya adalah berbantu OfficeSway. Aplikasi sway adalah pengembangan teknologi untuk pembelajaran secara online dengan sebagai sarana presentasi online. Budi Usodo, dkk (2016: 745) memberikan argumentasinya bahwa:

Aplikasi sway merupakan sarana presentasi yang dibuat dan diputar secara online pada laman sway.com. Hasil presentasi dapat dibagikan kepada penerima menggunakan link yang dibagikan. Di dalam laman sway.com, telah tersedia berbagai template design presentasi yang dapat dipilih oleh pembuat. Untuk menggunakan berbagai fitur pada sway.com, pengguna perlu membuat akun terlebih dahulu dan harus menggunakan email dengan outlock.com.

Senada dengan Kress dan Bezewr (dalam Diah Fakhmawati 2016: 3) bahwa 
Sway merupakan alat presentasi berbasis internet dengan berbagai fiturfitur sehingga ketika presentasi dijalankan dapat menggabungkan teks, gambar, video dan suara. Sway juga merupakan salah satu bentuk multimodal teks dimana berkombinasikan gambar dan bentuk tertentu.Sway termasuk kategori software sehingga dapat digunakan untuk membuat sebuah produk. Eko Lannueardy, 2015 dalam http: //id.news.qa1p.global.media.yaho o.com/sway-digital-storytelling-tooldari-microsoft-kini-hadir-

075940920.html) menjelaskan bahwa cara kerja sway sama dengan power point, yang membedakan fitur pendukungnya yang lebih banyak, pilihan desain lebih lengkap dan template tersedia berbagai model dan dapat digabungkan dengan versi online sehingga menghasilkan tampilan variatif.

Berdasarkan kajian tersebut, pengembangan media yang diolah online dengan menggunakanoffice Sway tujuannya untuk menghasilkan media yang menarik. Penguatan desain pembelajaran berbantu aplikasi online diyakini dapat mengupayakan pembelajaran IPS Sejarah menjadi bermakna dan menyenangkan serta akan memberikan penyegaran pengetahuan berkaitan dengan wawasan kebangsaan terutama kebudayaan Indis. Indis merupakan serapan dari bahasa Belanda yaitu Nederlandsch Indie. Suku kata ini umumnya dimaknai sebuah nama daerah jajahan Belanda diseberang lautan yang secara geografis meliputi kepulauan yang disebut Nerlandsch oost indie (Sukawi, 2009: 42). Rully Setiawan (2011: 15) berpendapat bahwa kebudayaan yang terbentuk sebagai akibat percampuran dari kebudayaan Eropa dan pribumi. Kebudayaan Indis adalah bagian sebuah akulturasi, sintesa atau asimilasi gaya budaya Belanda (eropa) yang masa itu akibat dari penjajahan bangsa Belanda di Indonesia. Selama itu pula mereka membangun relasi dengan penduduk sekitar. Bentuk interaksinya dapat melalui saluran perkawinan. Hal ini disebabkan persinggungan Indonesia dengan eropa berbeda dengan cina, arab, dan timur tengah yang terjadi melalui jalan damai, artinya persilangan budaya Indonesia dengan eropa melalui penjajahan dan orientalisme dalam praktik poskolonialisme (Dian Swandayani dkk, 2010). Kebudayaan Indis yang dimaksud adalah manifestasi beberapa bangunan kuno peninggalan Belanda. Terdapat pembagian bentuk gaya arsitektur dalam kebudayaan indis yang terperinci sebagaimana yang dijelaskan oleh Hadinoto (2010) seperti berikut ini: 
Table 1. Elemen Denah Bangunan

\begin{tabular}{|c|c|c|}
\hline $\begin{array}{c}\text { Gaya indische empire } \\
\text { (ages 18-19) }\end{array}$ & $\begin{array}{c}\text { Gaya arsitektur transisi } \\
(1890-1915)\end{array}$ & $\begin{array}{c}\text { Gaya arsitektur kolonial } \\
\text { modern (1915-1940) }\end{array}$ \\
\hline Simetri & Simetri & Tidak simetri (bervariasi) \\
\hline Central room & Teras mengelilingi & Tidak ada patio \\
\hline Teras mengelilingi & & Ada penahan sinar matahari \\
\hline \multicolumn{3}{|c|}{ Table 2 Elemen Tampak Bangunan } \\
\hline $\begin{array}{c}\text { Gaya indische empire } \\
\text { (ages 18-19) }\end{array}$ & $\begin{array}{c}\text { Gaya arsitektur transisi } \\
(1890-1915)\end{array}$ & $\begin{array}{c}\text { Gaya arsitektur kolonial } \\
\text { modern }(1915-1940)\end{array}$ \\
\hline $\begin{array}{l}\text { Dominance of greek } \\
\text { columns style }\end{array}$ & $\begin{array}{l}\text { To eliminate the greek } \\
\text { columns style }\end{array}$ & Unsymmetry \\
\hline Front porch (voor galerij) & Gevel & Clean design \\
\hline Rear terrace & Tower at the entrance & \\
\hline \multicolumn{3}{|l|}{ Symmetry } \\
\hline \multicolumn{3}{|c|}{ Tabel3. Elemen Material Bangunan } \\
\hline $\begin{array}{c}\text { Gaya indische empire } \\
\text { (ages 18-19) }\end{array}$ & $\begin{array}{c}\text { Gaya arsitektur transisi } \\
(1890-1915)\end{array}$ & $\begin{array}{c}\text { Gaya arsitektur kolonial } \\
\text { modern }(1915-1940)\end{array}$ \\
\hline Batu bata & Batu bata & Batu bata \\
\hline $\begin{array}{l}\text { Menggunakan kayu pada } \\
\text { kuda-kuda atap pintu dan } \\
\text { jendela }\end{array}$ & $\begin{array}{l}\text { Penggunaan dominan } \\
\text { kayu pada rangka atap, } \\
\text { pintu dan jendela }\end{array}$ & $\begin{array}{l}\text { Penggunaan kaca minim } \\
\text { terutama pada kaca jendela }\end{array}$ \\
\hline $\begin{array}{l}\text { Tidak banyak } \\
\text { menggunakan kaca }\end{array}$ & Menggunakan kaca & \\
\hline \multicolumn{3}{|c|}{ Table 4. Sistem Konstruksi } \\
\hline $\begin{array}{c}\text { Gaya indische empire } \\
\text { (ages 18-19) }\end{array}$ & $\begin{array}{c}\text { Gaya arsitektur } \\
\text { transisi }(1890-1915)\end{array}$ & $\begin{array}{c}\text { Gaya arsitektur kolonial modern } \\
(1915-1940)\end{array}$ \\
\hline $\begin{array}{l}\text { Dinding pemikul, kolom di } \\
\text { depan dan belakang }\end{array}$ & $\begin{array}{l}\text { Wall gevel-bearer } \\
\text { with conspicuous } \\
\text { front grevel }\end{array}$ & System konstruksi rangka \\
\hline $\begin{array}{l}\text { Using the column and } \\
\text { beam construction sistem }\end{array}$ & $\begin{array}{l}\text { Roofs: gable and } \\
\text { shield shape by using } \\
\text { a roof cover }\end{array}$ & $\begin{array}{l}\text { Roof: still dominated by a gable } \\
\text { roof cover material or shingles }\end{array}$ \\
\hline $\begin{array}{l}\text { Scute roof construcsion } \\
\text { with roof cover }\end{array}$ & $\begin{array}{l}\text { There are efforts to } \\
\text { use additional } \\
\text { construction as the } \\
\text { vents on the roof }\end{array}$ & $\begin{array}{l}\text { There are parts of the building } \\
\text { using concrete construction, using } \\
\text { the flat roof of the concrete } \\
\text { material, which has never existed }\end{array}$ \\
\hline
\end{tabular}

Berdasarkan konsep itu, menyebutkanPertama, model beberapa peninggalan budaya bangsa pengajaran IPS Sejarah masih berpotensi sebagai kebudayaan indis. konvensional dengan metode ceramah. Misalnya, Rumah Kauman di Semarang (Sukawi, 2009), GKJW Mojowarno di Jombang (Grace Mulyono dan Yohana Mandasari, 2011), serta Bekas Bank Indonesia di Solo (Reka Seprina, 2014). Berdasarkan informasi dan observasi tahun 2016 di Madiun Pendidik terasa belum memanfaatkan variasi media yang menarik dan interaktif sehingga menimbulkan kejenuhan. Kedua, keterbatasan pemanfaatan sumber ajar. Sumber belajar lingkungan sekitar dapat digunakan untuk pembelajaran IPS 
Sejarah seperti bangunan Indis (Perumahan Karyawan KA, Gedung sekolah SMPN 1 Madiun, Balai Kota, PLTA Giringan, pabrik gula pagotan dan kawedanan Uteran atau kebun Kopi kandangan).

Dengan demikian, Sway berkonten Indis adalah media kompilasi presentasi yang dibuat online yang content materitentang kebudayaan Indis. Sintesa media Sway berkonten Indis sebagai bantuan media pembelajaran berbasis IT diyakini mampu menumbuhkan efektivitas siswa dalam aspek motivasi dan prestasi belajar. Tujuan penelitian ini adalah untuk mengembangkan media pembelajaran IPS Sejarah berbantu office Sway dengan konten kebudayaan Indis. Pemilihan pengembangan media office sway berkonten indis, tujuan tak lain adalah sebagai konservasi dini peninggalan Indis sebagai bagian terbentuknya nilai sejarah peradaban bangsa.

\section{METODE}

Model penelitian yang digunakan adalah bentuk Research and Development (R\&D), dengan langkahlangkah dari Borg and Gall. Sugiyono (2013: 297) mengatakan bahwa metode penelitian dan pengembangan adalah model penelitian untuk menghasilkan produk tertentu, dan menguji keefektifan produk yang dihasilkan.
Lebih lanjut, untuk menguji produk yang masih bersifat hipotetik, maka digunakan tahap eksperimen, dan kemudian setelah melalui berbagai tahapan uji coba produk, maka output dari produk itu bisa diterapkan di lapangan melalui diseminasi. Metode yang digunakan dalam penelitian ini adalah deskriptif, evaluatif, dan eksperimental (I Gde Rasagama, 2011: 4). Tahap deskriptif digunakan untuk mengungkapkan dan menjelaskan temuan awal penelitan yang berada di lapangan, dan akan dinarasikan dalam bentuk catatan teks. Pemilihan metode evaluatif digunakan untuk mengevaluasi produk pengembangan melalui langkah uji coba. Metode evaluasi akan menggunakan teknik prosedural dengan menitikberatkan pada langkah-langkah yang memang harus diikuti untuk menghasilkan sebuah produk. Metode eksperimen digunakan untuk mengukur keampuhan produk pengembangan. pengukuran ini terdapat kelompok kontrol sebagai pembanding terhadap kelompok eksperimen. Di dalam konteks tersebut sebagai kunci dalam pengembangan dari produk ini yaitu, bilamana belum ada suatu keputusan layak atau tidak pada produk tersebut, maka proses produksi belum dapat dilakukan. Produk harus melewati beberapa tahapan validasi dan perbaikan. 
Prosedur pengembangan produk diimplementasikan pada tahapan penelitian yang telah dimodifikasi dari Borg and Gall yaitustudi pendahuluan dan tahap pengembangan. Kedua tahap ini meliputi persiapan, eksplorasi, dan penyusunan produk awal (Nugraheni, Herman Waluyo, Budi Waluyo dan Atikah, 2010: 32). Ketiga tahap evaluasi media. Gambar 2. Merupakan proses adaptasi dari siklus Borg and Gall sebagai berikut:

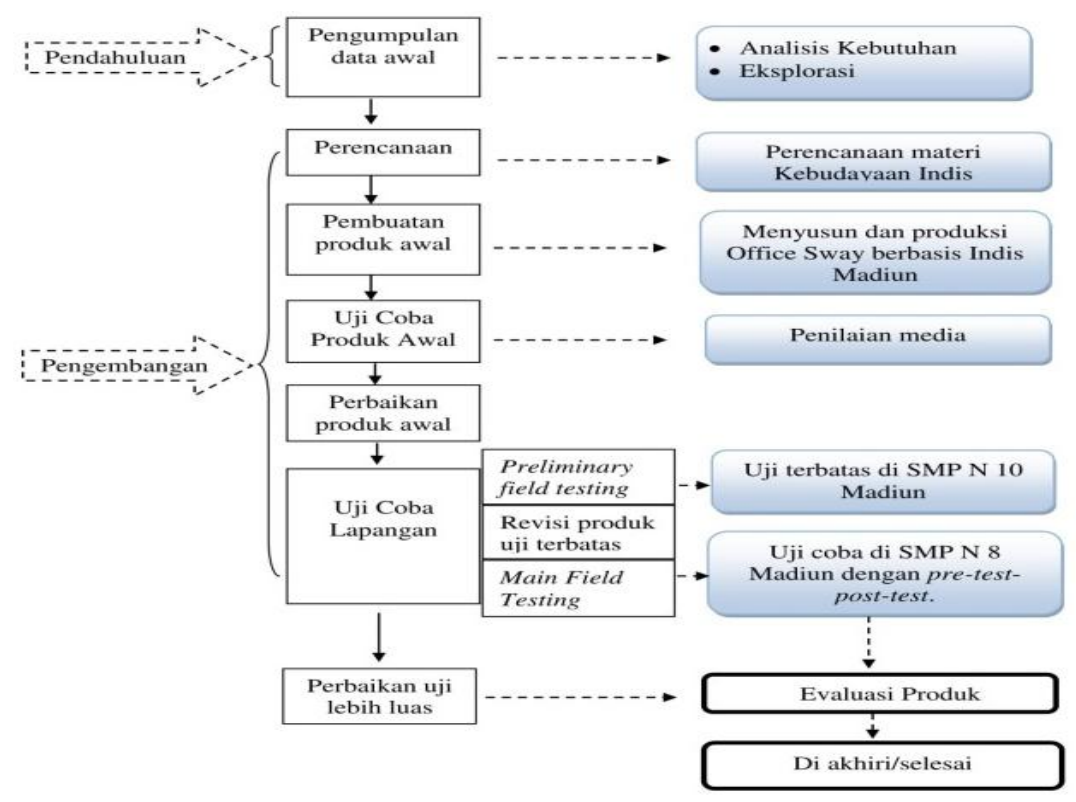

Gambar 1. Modifikasi dan adapatasi tahapan R\&D Borg and Gall (Borg and Gall, 2007)

Selajutnya pengembangan ini dibingkai melalui model hipotetik mengadopsi model “IDI" (instructional development institute), yaitu define, develop, dan evaluate (dalam Michael Molenda dan Elizabeth Boling, 2008: 106). Rancangan tahapan iniberjalan melalui tiga mekanisme, yaitu define (penerapan), pengembangan (develop), dan evaluasi produk (evaluate). Model define dilakukan identifikasi masalah meliputi uji analisis kebutuhan dengan sasaran siswa dan guru. Uji tersebutdigunakan untuk mengetahui teori das sein dan das sollendalam proses pembelajaran IPS Sejarah. Model desain pengembangan (develop), secara konseptual terdapat kegiatan yang dilakukan dengan membuat rancangan produk yang sifat masih abstrak yang merupakan bentuk prototype (draft produk) dan masih memerlukan penilaian sampai uji coba skala terbatas dan skala diperluas. Evaluasi (evaluate) yaitu melakukan penilaian dengan menguji draft produk/prototype agar siap diterapkan.

Adapun bagan model IDI (instructional development institute) yang telah dimodifikasi untuk 
pengembangan produk media adalah sebagai berikut: pembelajaran Sway berkonten Indis

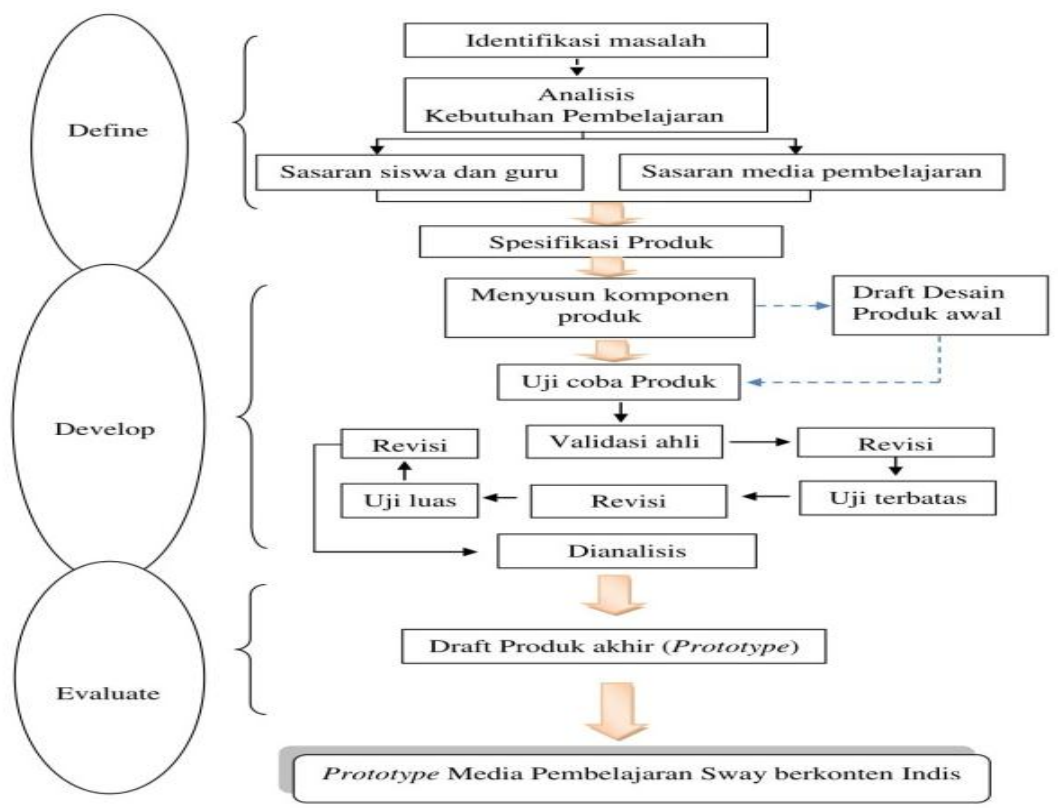

Gambar 2. Model Hipotetik Media Office Sway berkonten Indismodifikasi dari model instructional development institute (IDI) (Michael Molenda dan Elizabeth Boling, 2008: 106)

\section{HASIL DAN PEMBAHASAN}

\section{Konstelasi Produk Microsoft Office} Sway berbasis Indis

Hakikatnya penggunaan office sway memiliki perbedaan dibandingkan dengan power point. Sway sedikit lebih baik untuk menampilkan kreasi sesuai kebutuhan. Hal ini dinyatakan dalam perbandingan dengan Microsoft power point mempunyai kelebihan seperti tampilan dan fitur-fitur template yang digunakan. Terlepas dari hal itu, maka sway berkonten kebudayaanIndis memberikan peluang untuk dimanfaatkan sebagai bahan pembelajaran IPS Sejarah. Adapun contoh tampilan penggunaan office sway berkonten Indis dapat dilihat pada gambar berikut ini:

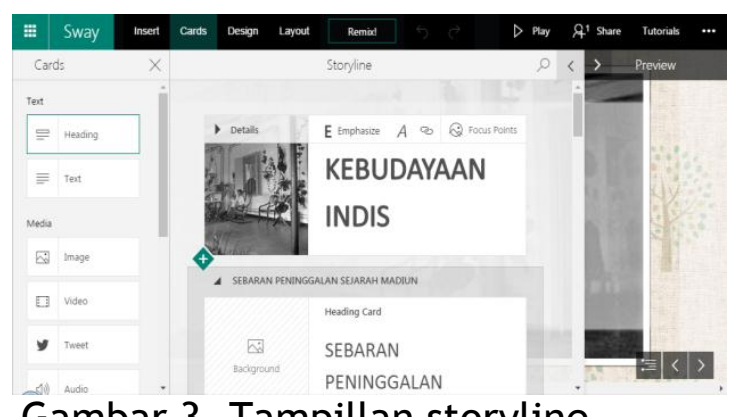

Gambar 3. Tampillan storyline

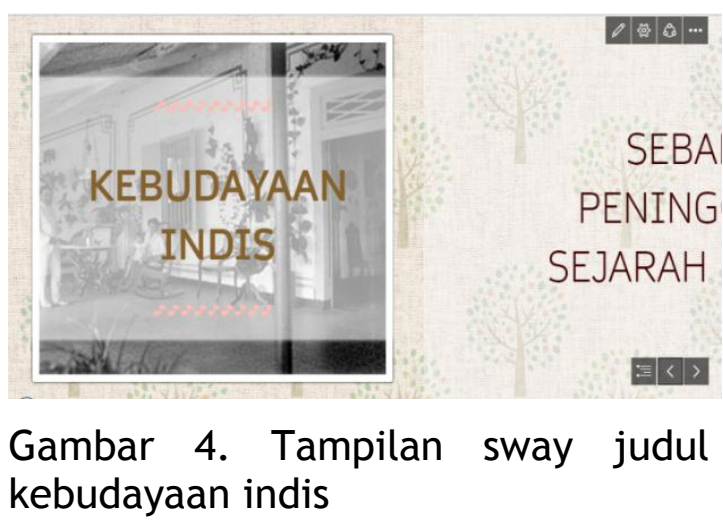




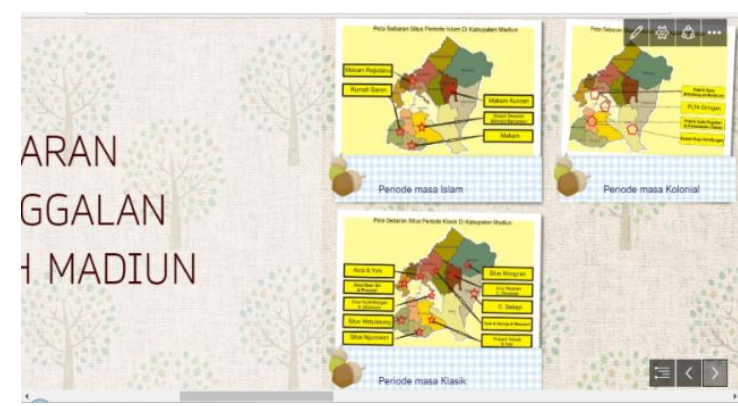

Gambar 5. Tampilan sway daerah sebaran Indis di Madiun

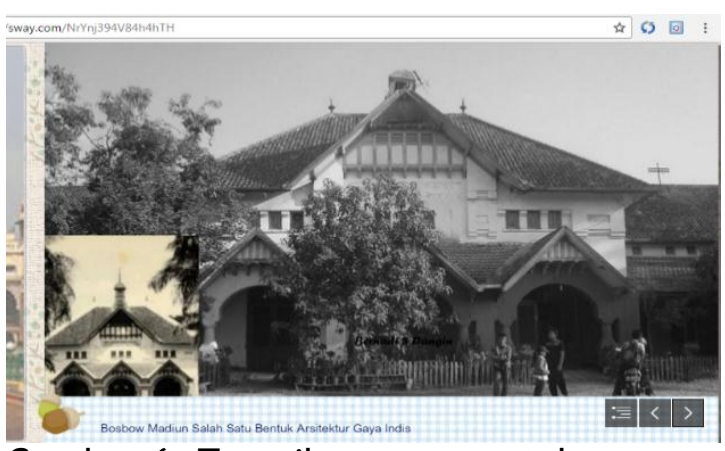

Gambar 6. Tampilan sway contoh budaya Indis

\section{Uji Coba Lapangan}

\section{Hasil Uji Skala Terbatas (Preliminary Field Test)}

Uji coba skala terbatas menggunakan sampel15 siswa SMP Negeri 10 Madiun. Pada uji coba tersebut memberikan informasi awal mengenaikelayakan media Sway berbasis Indisuntuk diberlakukan ketahap berikutnya. Tahap ini bertujuan untuk memperoleh bukti kelayakan produk awal secara terbatas dengan menggunakan eksperimen model Single One-Shot Case Study. Gambar 7 menunjukkan Design single One-Shot Case Study:

\section{X $\mathbf{0}$}

Gambar 7. Design single One-Shot Case Study

Sumber: Sugiyono, 2013: 110

Keterangan

$\mathrm{X}$ : Treatment yang diberikan (variable independen)

O: Observasi (Variabel dependen)

Data yang diperoleh dari tahap ini adalah hasil angket dan pengamatan, disusun dan dianalisis untuk dijadikan data awal guna merevisi produk.

1) Instrumen

Instrumen yang digunakan adalah lembar observasi dan kuesioner. Lembar observasi digunakan mencatat kejadian dan respon siswa dalam proses uji coba produk. Instrumen kuesioner bertujuan untuk mengevaluasi kualitas media sway berkonten Indis.

2) Teknik Analisis Data

Data hasil penelitian merupakan respon siswa secara random yang dijadikan sampel. Data berupa hasil saran dan pengamatan saat $u j i$ coba,dianalisis secara kuantitatif dan deskriptif-kualitatif, dan disimpulkan untuk perbaikan. Pedoman yang digunakan dalam menarasikan arti kuantitatif adalah sebagai berikut:

Tabel 5. Patokan perhitungan persentase skala lima

\begin{tabular}{c|c|c|c}
\hline \multirow{2}{*}{$\begin{array}{c}\text { Interval persentase } \\
\text { tingkat penilaian }\end{array}$} & \multicolumn{2}{|c|}{ Nilai ubah skala } & \multirow{2}{*}{ Keterangan } \\
\cline { 2 - 3 } & $1-5$ & E-A & Baik sekali \\
\hline $85 \%-100 \%$ & 5 & $\mathrm{~A}$ & Baik \\
\hline $75 \%-84 \%$ & 4 & $\mathrm{~B}$ & Cukup \\
\hline $60 \%-74 \%$ & 3 & $\mathrm{C}$ & Kurang \\
\hline $40 \%-59 \%$ & 2 & $\mathrm{D}$ & \\
\hline
\end{tabular}




\begin{tabular}{c|c|c|c}
\hline $0 \%-39 \%$ & 1 & $E$ & Sangat kurang \\
\hline
\end{tabular}

Interpretasi tersebut mengadaptasi kategori yang penilaian intervalnya sebagai berikut :

0

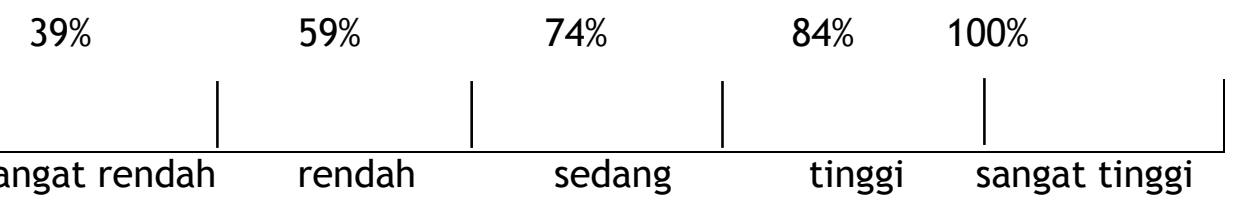

Gambar 8. Adaptasi model penilaian interval

(Iskandar, 2013: 96)

Pedoman konversi mengacu pada Sukardjo (2006)sesuai tabel berikut ini:

Tabel 6. Pedoman konversi nilai kelayakan produk menjadi data kualitatif

\begin{tabular}{c|c|l}
\hline Nilai & Data Kualitatif & \multicolumn{1}{c}{ Data Kuantitatif } \\
\hline A & Sangat Baik & $X>4,21$ \\
\hline B & Baik & $3,41 \geq X \leq 4,21$ \\
\hline C & Cukup Baik & $2,61 \geq X \leq 3,40$ \\
\hline K & Kurang & $1,80 \geq X \leq 2,60$ \\
\hline S & Sangat Kurang & $X \leq 1,79$ \\
\hline
\end{tabular}

Keterangan :

Skor Maksimal $=5 \quad X i=1 / 2(5+1)=3 \quad X=$ Skor Aktual

Skor Minimal $=1 \quad \mathrm{Sb} i=1 / 6(5-1)=0,67$

Berdasarakan proses uji coba untuk hasil perolehan uji skala terbatas produk Sway berkonten Indis, maka dapat dilihat pada table 3:

Tabel 7. Data Perolehan Angket Uji Coba Terbatas

\begin{tabular}{|c|c|c|c|c|c|}
\hline \multirow[t]{2}{*}{ Kriteria Penilaian } & \multicolumn{5}{|c|}{ Skala Penilaian } \\
\hline & 1 & 2 & 3 & 4 & 5 \\
\hline Penyampaian materi sistematis & 0 & 0 & 4 & 7 & 4 \\
\hline Penyampaian materi menarik & 0 & 0 & 4 & 3 & 8 \\
\hline Media dapat memotivasi belajar & 0 & 0 & 3 & 8 & 4 \\
\hline Materi menarik & 0 & 0 & 2 & 8 & 7 \\
\hline Kejelasan bahasa untuk memahami materi & 0 & 0 & 4 & 7 & 4 \\
\hline Materi mudah & 0 & 0 & 2 & 9 & 4 \\
\hline Materi mampu mengubah pengetahuan & 0 & 0 & 1 & 7 & 7 \\
\hline Mudah menggunakan media & 0 & 1 & 0 & 11 & 7 \\
\hline Ukuran huruf dan tulisan & 0 & 1 & 2 & 7 & 8 \\
\hline Kombinasi warna & 0 & 1 & 3 & 7 & 8 \\
\hline Kualitas gambar & 0 & 0 & 3 & 7 & 8 \\
\hline Kualitas tampilan Sway & 0 & 0 & 3 & 8 & 8 \\
\hline Jumlah skor & & 3 & 30 & 89 & 77 \\
\hline Jumlah x skala Penilaian & & 6 & 90 & 353 & 375 \\
\hline Total & \multicolumn{5}{|c|}{824} \\
\hline Rerata & \multicolumn{5}{|c|}{4,23} \\
\hline Keterangan & \multicolumn{5}{|c|}{ Sangat baik } \\
\hline
\end{tabular}

(Angket Siswa Uji Coba Terbatas) 
Hasil perhitungan data yang diperoleh konversi mendapat skor 4,23. Sesuai Kriteria pedoman konversi, skor menunjukaan sangat baik ( $X>4,21)$ sehingga media sway berkonten Indis dianggap layak untuk pembelajaran IPS Sejarah.

\section{Hasil Uji Coba Skala Diperluas (Main Field Test)}

Tahap ini disebut juga uji skala diperluas untuk menghasilkan draft (prototype) media sway berbasis Indis.Uji skala diperluaas menggunakan metode preexperimental design (nondesigns) tipe One-GroupPretestposttestdesign, dengan alasan pengambilan data hanya membandingkan keadaan sebelum dan sesudah diberi perlakuan. Gambar 9 menunjukkan tipe one-group pretestposttest design:

\section{$\mathrm{O}_{1} \quad \mathbf{X} \quad \mathrm{O}_{2}$}

Gambar 9. Desain One-Group pretest-postest (Sugiyono, 2013: 110) Keterangan:

$\mathrm{O}_{1} \quad$ : Nilai Pre-test (keadaan sebelum diberi perlakuan)

$\mathrm{O}_{2} \quad$ : Nilai Post-test (setelah diberi perlakuan)

X : Treatment (menggunakan media video).

Pengujian produk dilaksanakandi SMPNegeri 8 Madiun dengan alat ukurnya adalah tes prestasi kognitif. Model perhitungan adalah Paired Samples $T$ Test (Non-Independent) dengan uji statistik jenis parametrik. Statistik parametrik mensyaratkan dua hal yaitu data harus berdistribusi normal dan homogen. Uji normalitas menggunakan teknik one sample kolmogorov-smirnovdan uji homogenitas menggunakan oneway anovadan aplikasi SPSS sebagai bantuan alat penghitungnya. Analisis hipotesisnya adalah:

a) Hipotesis Uji
$H_{o}=$ Tidak ada peningkatan signifikan nilai siswa sebelum diberi dan setelah diberi media yang dikembangkan.

$H_{1}=$ Ada peningkatansignifikan nilai siswa sebelum dan sesudah diberi media yang dikembangkan.

b) Taraf signifikansi $\alpha=5 \%$

c) Keputusan uji

$H_{0}$ diterima bila signifikansi $>0,05$

$H_{0}$ ditolak bila signifikansi $<0,05$

Berdasarkan pelakasanaan uji di SMP Negeri 8 Madiun dengan sampel 28 siswa menunjukkan nilai rerata 60,35 (pre-test) dan 94,46 (post-test), 
selanjutnya dilakukan uji statistik model Paired Samples $T$ Test (NonIndependent). Sebelum dilakukan perhitungan, sehubungan model parametrik mensyaratkan uji normalitas untuk mengetahui sebaran databerdistribusi normal. Uji normalitas menggunakan model One-Sample Kolmogorov-Smirnov Test yang hasilnya berikut ini:

One-Sample Kolmogorov-Smirnov Test

\begin{tabular}{ll|r|r}
\hline & & Pre Test & Post Test \\
\hline $\mathrm{N}$ & & 28 & 28 \\
Normal Parameters ${ }^{\mathrm{a}}$ & Mean & 60.3571 & 94.4643 \\
& Std. Deviation & 14.96469 & 4.97015 \\
Most Extreme Differences & Absolute & .240 & .221 \\
& Positive & .128 & .137 \\
& Negative & -.240 & -.221 \\
Kolmogorov-Smirnov Z & & 1.272 & 1.172 \\
Asymp. Sig. (2-tailed) & & .078 & .128 \\
\hline
\end{tabular}

a. Test distribution is Normal.

Data dianggap berdistribusi normal bila hitung statistik menghasilkan signifikansi>0,05., maka nilai signifikansi pre-test adalah 0.078 dan post-test adalah 0.128 . sehingga kesimpulannya data dinyatakan berdistribusi normal. Kemudian diuji menggunakan uji t dengan jenis statistik adalah Paired Sample T Test sebagai berikut:

t-test Paired Samples Statistics

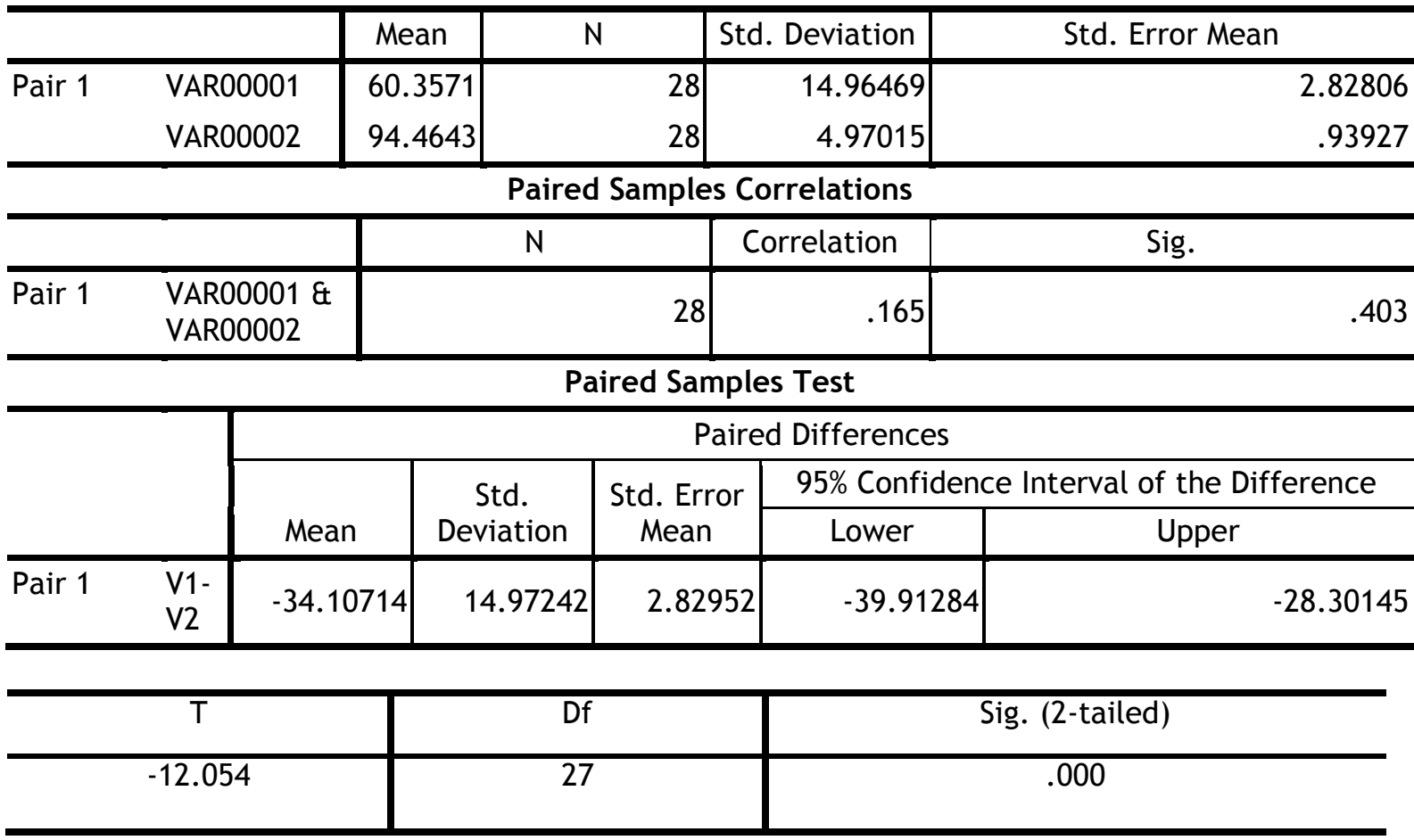


Berdasarkan hasil tersebut, bahwa nilai signifikansinya adalah 0.00 , sehingga perhitungannya menunjukkan lebih kecil dari 0,05, dan artinya $H_{0}$ ditolak sehingga telah terjadi peningkatan yang signifikan.

Perlunya Mengembangkan Media Sway berbasis Indis

Guru IPS diupayakan memiliki kemampuan dalam merancang pembelajaran dengan Microsoft Sway sebagai alternative media pembelajaran. Pemanfaatannya, tidak hanya terbatas padabuku teks atau power point, tetapi diupayakan dengan menggabungkan beberapa layanan aplikasi digital yang lain salah satunya adalah layanan Office Sway. Berkaitan dengan hal tersebut, salah satu yang formulasi yang dapat digunakan untuk pembelajaran IPS Sejarah adalah Sway berbasis kebudayaan Indis. Guru sebagai penyalur informasi perlu menyampaikan wawasan kebudayaan Indis berkonten lokal, mengingat dibeberapa daerah di Indonesia masih banyak dijumpai peninggalan bergaya arsitektur Indis yang perlu dilakukan recovery untuk pembelajaran Sejarah.Arah dan tujuannya adalah untuk efektifnya pengajaran yang mempunyai nilai-nilai kebermaknaan. Pengajaran yang efektif juga didorong oleh kemampuan guru meredesain model melalui perantara media yang inovatif agar peserta didik nyaman. Kebutuhan tutorial online banyak diperoleh, tergantung upaya guru dalam eksplorasi materi terutama kebudayaan Indis.

Dengan demikian kebutuhan seorang pendidik untuk mengembangkan media pembelajaran dengan memadukan digitalisasi untuk membuat produk yang menarik mau tidak mau memang diperlukan. Hal ini menandakan bahwa Media pembelajaran mempunyai peranan penting bagi dunia pendidikan. Media pembelajaran digunakan sebagai sarana pendidik untuk membantu menyampaikan materi dalam proses pembelajaran kepada peserta didik. Penggunaan media yang bervariasi dapat menjadikan kegiatan pengajaran menjadi bermakna. Apalagi saat ini perkembangan teknologi yang pesat, tentu dapat bermanfaat untuk menciptakan media yang variatif.Perlu diketahui pula berdasarkan pendapat Dewi Immaniar Desrianti, Untung Rahardja, dan Reni Mulyani (dalam Jurnal CCIT, 2012: 124) mengemukakan bahwa saat ini sistem pendidikan dan cara penyampaian dalam sebuah pengajaran yang digunakan masih bersifat konvensional, oleh sebab itu dibutuhkan sebuah sistem dan cara pengajaran model baru yang memiliki unsur modern. Pengajaran model baru yang memiliki unsur modern menurut kebutuhan saat ini, tidak terlepas dari pendekatan IPTEK. Pendidik bisa juga melakukan redesain model 
pembaharuan pengajaran, dengan penggunakan media bersifat modern sepertiaplikasi media Microsoft office sway.

Di era kekinian kebutuhan pola pembelajaran yang modern diperlukan oleh peserta didik. Pola pembelajaran yang menarik juga dapat menguntungkan peserta didik diantaranya keberhasilan mencapai tujuan pembelajaran dan pemahaman materi dapat tercapai, serta meminimkan kejenuhan yang dirasakan selama ini.Martinis Yamin (2011: 330) yang mengungkapkan bahwa mata pelajaran IPS Sejarah dilihat dari tujuan pendidikan adalah untuk mengembangkan pengetahuan, pemahaman, dan kemampuan analisis peserta didik terhadap kondisi sosial masyarakat. Keterkaitan kedua pendapat tersebut, semakin mempertegas bahwa belajar IPS Sejarah berfungsi untuk mengembangkan pengetahuan kemampuan berpikir logis terhadap situasi dan kondisi masyarakat. Secara tidak langsung pengertian tersebut mempunyai penguatan dalam ranah pengajaran konstruktivisme. Tidak heran jika pola pembelajaran saat ini mengadopsi konsep konvensional terus menerus, berarti dapat memotong mata rantai dari teori belajar konstruktif dan tidak mungkin menimbulkan nilai-nilai kebermaknaan. Hal ini disebabkan tema- tema IPS Sejarah begitu kompleks dan universal sesuai periodesasi sistematik dari masa ke masa yang dapat dirasakan hingga kekinian.

Berkaitan dengan konteks kekinian memaknai wawasan kebangsaan melalui contoh peninggalan budaya masa lampau seperti kebudayaan Indis perlu diwariskan ke generasi sekarang. Tujuannya tak lain adalah memperkuat pemahaman dinamika historiografi masa lampau yang dimiliki bangsa. Sebaran benda kebudayaan Indis yang bernilai sejarah memang banyak dan beragam. Penanaman nilai kebangsaan dengan visualisasi

berbasiskebudayaanIndissangat penting diberikan kepada peserta didik. Pentingnya untuk menginternalisasi materi peninggalan kebangsaan berkonsep budaya Indis, juga dikemukakan oleh Heddy Shri AhimsaPutra (2014: 4) berikut ini:

"Budaya kawasan ini perlu diketahui, dipahami oleh generasi muda Indonesia, dan bagi mereka yang berasal dari kawasan tersebut, budaya itu perlu menjadi salah satu sistem acuan budaya mereka agar tidak terasing dari masyarakat di sekeliling mereka yang telah memlihara dan membesarkan mereka dengan berbagai kearifan lokalnya. mengabaikan nilai budaya kawasan ini akan dapat membuat sebagian generasi muda Indonesia kehilangan jatidiri dan kehilangan orientasi budaya dalam kehidupannya sehari-hari". 
Pengembangan media office sway berbasis Indis ini menggunakan Model IDI (institute development instructional). Model IDI diaplikasikan dengan prosedur dari siklus Borg and Gall yang telah termodifikasi menjadi beberapa langkah sesuaikebutuhan. Keberhasilan dalam tahap ujicoba yang dilakukan membuktikan bahwa aplikasi office Sway merupakan salah satu variasi bentuk media pembelajaran yang sangat penting dan berpengaruh. Secara empirik, media office Sway kebudayaan Indis menawarkan sajian pengajaran digitalsehingga dapat menimbulkan pembaharuan pengetahuan serta motivasi peserta didik. Pada satu sisi, peranan media secara teoritik telah disinggung oleh Edgar Dale melalui teori "cone of experience". Teori tersebut menjadi sarana pendidik untuk menentukan model pengajaran seperti apa agar ketercapaian pengetahuan dapat tercapai.

Edgar Dale (dalam Wina Sanjaya, 2008: 199-200) menjelaskan bahwa pengalaman belajar yang diperoleh siswa dapat melalui proses perbuatan atau mengalami sendiri apa yang dipelajari, proses mengamati dan mendengarkan melalui media tertentu dan proses mendengarkan melalui bahasa. Berdasarkan penyataan tersebut, konsep dari teori "cone of experience" dapat memberikan gambaran bahwa bilamanapeserta didik diberi contoh materi secara konkret dan dengan tampilan yang menarik, maka mereka dapat memperoleh pengalaman belajar yang bermakna.

Jamil Suprihatiningrum (2013: 321) menyebutkan pula bahwa secara hierarki nilai pengalaman tingkatan tertinggi dari konsep media pembelajaran adalah melalui pengalaman konkret, sedangkan tingkatan terendah melalui pengalaman yang paling abstrak. Salah satu hasil riset Francis Donkoryang telah dilakukan sebelumnya dengan judul "The comparative instructional effectiveness of print-based and video-based instructional materials for teaching practical skills at a distance", menunjukkan keterampilan praktis yang diperoleh secara signifikan lebih tinggi dengan penggunaan bahan ajar aplikasi digitalisasi. Apalikasi digitalisasi berupa video yang telah ditampilkan ternyata dapat membantu mempengaruhi keahlian dengan bukti nilai signifikan lebih unggul. Selanjutnya, hasil dari pengujian empirik tersebut menyatakan bahwa media office Sway kebudayaan Indis memiliki keunggulan dibandingkan beberapa media lain seperti power point. Keunggulan tersebut diantaranya (1). Desain tampilan obyek sangat menarik sehingga dapat menimbulkan kebermenarikanpengajaran Sejarah, dan (2). Fitur-fitur yang disajikan pun dapat merangsang otak siswa untuk memiliki 
ketertarikan terus menerus mempelajari IPS Sejarah yang selama ini sedikit menjenuhkan, dan (3) pada Office Sway Indis dapat dipadukan dengan submit video online yang bisa dimunculkan pada lembar kerja Sway serta dapat dibagikan ke pengguna lain dan dinikmati dalam versi online sehingga semakin menambah nilai-nilai estetika dalam produksi media yang dikembangkan.

\section{PENUTUP}

\section{Simpulan}

Media pembelajaran office sway berkonten Indis merupakan pengembangan desai media berkonten hasil kebudayaan Indis yang dikemas dengan aplikasi Microsoft Sway. Kekuatan media ini adalah dari segi tampilan desain, fitur-fitur penggunaannya serta bisa dikombinasikan dengan video lain yang bisa disajikan melalui online sehingga sangat berbeda dengan power point. Selain itu, media ini mempunyai kekuatan pada wawasan kebangsaan terutama hasil kebudayaan Indis yang kedengaran asing di telinga siswa. Berdasarkan hasil penelitian yang dilakukan bahwa media sway berbasis Indis layak untuk dijadikan alternatif media pembelajaran IPS Sejarah di Madiun. Hal ini dibuktikan dari hasil perhitungan data dari uji terbatas yang diperoleh konversi mendapat skor rerata 4,23.Sesuai pedoman konversi, skor sangat baik $(X>4,21)$ sehingga media sway berkonten Indis dianggap layak untuk pembelajaran IPS Sejarah. Kemudian, dilanjutkan uji skala diperluas yang dilakukan di SMP Negeri 8 Madiun dengan sampel 28 siswa menunjukkan nilai rerata 60,35 (pretest) dan 94,46 (post-test),yang selanjutnya dilakukan uji statistik model Paired Samples $T$ Test (NonIndependent). Hasilnya menunjukkan bahwa nilai signifikansi adalah 0.00 , sehingga hasil perhitunganmenunjukkan lebih kecil dari 0,05, dan artinya $H_{0}$ ditolaksehingga telah terjadi peningkatan yang signifikan. Kesimpulannya adalah bahwa media Sway berbasi kebudayaan Indis layak dan dapat digunakan untuk pembelajaran IPS Sejarah.

Saran

Pada prinsipnya tahapan pengembangan media pembelajaran Sway berbasis Indis hanya pada langkah menghasilkan draft prototype (uji skala terbatas dan skala diperluas dalam scope kecil) dimana dapat meningkatkan prestasi belajar siswa SMP Negeri 8 Madiun. Untuk itu perlu dilakukan pengembangan penelitian lanjutan hingga langkah uji efektivitas dan diseminasi produk sehingga produk yang dihasilkan dapat meningkat sangat signifikan baik dari segi substansi maupun desainnya.

\section{Daftar Pustaka}


Borg, Walter \& Gall, Meredith Damien. 2007. Educational Research. New York: Longman.

Budi Usodo, Sutopo, Henny Ekana C, Ira Kurniawati dan Yemi Kuswardi. 2016. Pelatihan Penerapan Beberapa Aplikasi Dari Microsoft: Office Mix, Onenote, Sway Dalam Pembelajaran Bagi Guru-Guru Matematika SMA Di Kabupaten Sragen. Jurnal Elektronik Pembelajaran Matematika, Volume 4 nomor 9 November 2016: 743-752.

Dewi Immaniar Desrianti, Untung Rahardja, dan Reni Mulyani. 2012. Audio Visual As One Of The Teaching Resources On Ilearning. Journal CCIT. Nomor 2 Volume 5 Januari 2012: 124-144.

Diah Fakhmawati 2016. Pembelajaran Berbasis Proyek: Membuat Sway TentangTanaman.(Online).Dalam 04.215.252.6/... / Pbp\%20membu at\%20sway\%20tentang\%20tanama n. Diakses 21 Juni 2016.

Dian Swandayani, Imam Santoso, dan Nurhadi. 2010. Kebudayaan Eropa Dalam Media Massa Indonesia Pada Awal Abad XXI. Makalah ini disampaikan dalam Konferensi International Kesustraan HISKI XXI. Surabaya: Universitas Airlangga Surabaya.

Donkor, Francis. 2010. The Comparative Instructional Effectiveness of Print-Based And Video-Based Instructional Materials For Teaching Practical Skills At A Distance. The International Review Of Research In Open And Distance Learning. Vol 11, No 1 2010 March:1-11.(Online), www.irrodl.org/index.php/irrodl /rt/printerFriendly/792/1486 (diakases 6 Mei 2016).

Eko Lannueardy. 2015. Sway, Digital Storytelling Tool Dari Microsoft Kini Hadir Di Windows 10. (Online) dalam Http://Id.News.Qa1p.Global.Med ia.Yahoo.Com/Sway-Digital-
Storytelling-Tool-Dari-Microsoft-

Kini-Hadir-075940920. Html

Diakses 22 Juni 2016

Erna Febry Aries S. 2011. Asesmen dan Evaluasi. Malang: Aditya Media Publishing

Grace Mulyono dan Yohana Mandasari. 2011. Perwujudan Budaya Indis Pada Interior Gereja Kristen Jawi Wetan Mojowarno. Dimensi Interior, 9: 24-33.

Hadinoto. 2010. Arsitektur Dan KotaKota Di Jawa Pada Masa Kolonial. Yogyakarta: Graha Ilmu.

Heddy Shri Ahimsa-Putra. 2014. Sumber Nilai Budaya Dan Nilai Budaya Untuk Generasi Muda Indonesia. Makalah disampaikan dalam Kongres Pendidikan, Pengajaan dan Kebudayaan II, Yogyakarta, 5 Mei 2014.

I Gde Rasagama. 2011. Memahami Implementasi Educational Research And Development. Makalah disampaikan dalam Kegiatan Pelatihan Metodologi Penelitian Untuk Dosen Unit Pelayanan Mata Kuliah Umum dan Unit Lainnya. Politeknik Negeri Bandung: 16 Agustus 2011.

Iskandar. 2013. Metodologi Penelitian Pendidikan dan Sosial. Jakarta: Referensia.

Jamil Suprihatiningrum. 2013. Strategi Pembelajaran : Teori dan Aplikasi. Yogyakarta: Ar-Ruzz Media.

Martinis Yamin. 2011. Paradigma Baru Pembelajaran. Jakarta: Gaung Persada Press

Molenda, Michael and Boling, Elizabeth. 2008. Creating. hal 81-139. dalam Alan Januszewski and Michael Molenda (Eds.). Educational Technology: A Definition with Commentary. London: Lawrence Erlbaum Associates. 
Novi Triana Habsari dan Khoirul Huda. 2015. Graphic Recorder Indis sebagai Inovasi Media Pembelajaran IPS berbasis Wawasan Kebangsaan. Prosiding. Dalam Semnasdik Inovasi pembelajaran untuk pendidikan yang berkemajuan 2015: Universitas Muhammadiyah Ponorogo.

Nugraheni, Herman Waluyo, Budi Waluyo, dan Atikah. 2010. Pengembangan Teater Tradisional Ketoprak Dengan Pendekatan Teatrikal, Tekstual, dan Sosiobudaya Untuk Menumbuhkan Industri Kreatif Seni Budaya. Top Riset: Pemanfaatan Hasil-Hasil Penelitian Unggulan Universitas Sebelas Maret. LPPM UNS: 27-36.

Rully Setiawan. 2011. Memudarnya pengaruh Masyarakat Belanda di Jakarta pada 1950-an: Studi kasus masalah Repatriasi. Skripsi. Jakarta: Program Studi Ilmu Sejarah UI.

Sugiyono. 2013. Metode Penelitian Pendidikan: Pendekatan Kuantitatif, Kualitatif, dan R\&D. Bandung: Alfabeta.

Sukardjo. 2005. Evaluasi Pembelajaran. Diktat Mata Kuliah Evaluasi Pembelajaran: Prodi Teknologi Pendidikan PPs UNY. (Unpublished).

Sukawi. 2009. Pengaruh Arsitektur Indis Pada Rumah Kauman Semarang: Studi Kasus Rumah Tinggal Jalan Suroyudan 55 Kampung Kauman. Tesa Arsitektur, 7: 41-50.

Wina Sanjaya. 2008. Perencanaan dan Desain Sistem Pembelajaran. Jakarta: Kencana Prenada Media Group. 